\title{
25 Research Suare \\ Kinetics And Monte Carlo Simulation of UV \\ Disinfection B. Subtilis Spores And SARS-CoV-2 In Dried Saliva Droplets
}

John Gibson ( $\nabla$ jh.gibson@utoronto.ca )

University of Toronto https://orcid.org/0000-0003-0915-8130

Ramin Farnood

University of Toronto

Benoit Barbeau

Polytechnique Montréal: Polytechnique Montreal

\section{Research Article}

Keywords: COVID-19, UV disinfection, aerosols, droplets, kinetics, surfaces

Posted Date: July 23rd, 2021

DOI: https://doi.org/10.21203/rs.3.rs-671658/v1

License: (c) (i) This work is licensed under a Creative Commons Attribution 4.0 International License.

Read Full License 


\section{Abstract}

Surfaces can be contaminated by droplets produced coughing or sneezing. In this short, exploratory work, UV disinfection data from $B$. subtilis spores in dried saliva droplets were fitted to a first-order model. The model has a disinfection rate constant for single organisms, and a smaller one for aggregates $\left(R^{2} \geq\right.$ 0.97). Changes in the fraction of organisms in aggregates $(\beta)$ alone could account for the effects of different sized droplets in the experimental work. Since a wide spectrum of droplet sizes can be produced and some of the rate constants were uncertain, Monte Carlo simulation was used estimate the UV inactivation performance in dried saliva droplets in a range of conditions. Using conservative lognormal distribution for $\beta$, the model was applied to the UV disinfection of SARS-CoV-2 in dried droplets. It was shown that one-log reduction of SARS-CoV-2 was very likely $(p>99.9 \%)$ and two-log reduction was probable $(p=75 \%)$ at a dose of $60 \mathrm{~mJ} / \mathrm{cm}^{2}$. Aggregates tend to be variable and limit the log reductions that can be achieved at high UV doses.

\section{Introduction}

We are in what is now, hopefully, the final stages of a global pandemic of the novel human coronavirus, known as Severe Acute Respiratory Syndrome Coronavirus 2 (SARS-CoV-2). This is the latest in a series of coronavirus outbreaks that also includes Severe Acute Respiratory Syndrome (SARS CoV-1) and Middle East Respiratory Syndrome (MERS) (Noorimotlagh, 2020). It is reasonable to expect more outbreaks in the future, and methods to control the spread of these viruses are important areas for research.

UV radiation, particularly at a wavelength of $254 \mathrm{~nm}$, has long been understood to be absorbed by the pyrimidine bases, thymine in DNA and uracil in RNA, causing dimers that slow or halt reproduction (Jagger, 1967; Masschelein, 2002). When it comes to viruses, Pfaender et al. (2015) showed direct damage of the hepatitis C virus genome, slowing replication after UV treatment. Beck et al. (2016) showed RNA damage of the bacteriophage MS2 after UV treatment at wavelengths of 210 and $290 \mathrm{~nm}$.

Many viruses, including SARS-CoV-2, have been shown to persist on surfaces for several days (Noorimotlagh, 2020). One source of surface contamination is droplets produced by speaking, sneezing, or coughing (Dbouk and Drikakis, 2020; Johnson et al., 2011). The ability of UV to disinfect viral pathogens in dried droplets remains largely absent from the current literature. Ma et al. (2021), after exploring the UV disinfection of the MHV, Phi6, and coronavirus HCoV 299E in liquid suspensions, suggest a need for better understanding UV disinfection on surfaces. A recent meta-analysis by Chiappa et al. (2021) report that just $11 \%$ (2 of 18) of the selected studies examined the effects of UV on viruses in dried droplets, with the majority (14 of 18) using liquid suspensions. The two dried droplets studies focused on demonstrating new technologies: a rotating full-room disinfector (Bedell et al., 2016) and a pulsed xenon emitter (Simmons et al., 2021). Though both studies were able to show reductions in coronaviruses, their unique emitters make it difficulty to apply these results elsewhere. 
Experimental work on dried droplets is challenging due to the small size of the droplets and the large number of variables. Johnson et al. (2011) showed that the largest droplets produced by speaking had a mode diameter of just $145 \mu \mathrm{m}$, corresponding to a volume of just $0.0016 \mu \mathrm{L}$. Lab work with such small volumes is challenging. The ASTM test E3135-18 Standard Practice for Determining Antimicrobial Efficacy of Ultraviolet Germicidal Irradiation Against Microorganisms on Carriers with Simulated Soil suggests using droplets of $1 \mu \mathrm{L}$ instead. ASTM test E2721-16 Standard Practice for Evaluation of Effectiveness of Decontamination Procedures for Surfaces When Challenged with Droplets Containing Human Pathogenic Viruses aims to produce droplets $15 \mu \mathrm{m}$ in diameter. However, this is done by atomizing the virus, which is potentially hazardous if they were to escape before, during, or after the experiment. Significant losses are also observed during the aerosolization procedure. In addition, Barancheshme et al. (2021) showed there is wide variability in the UV transmission of human saliva, another source of variability in experiments.

Computer modeling can inform us about UV disinfection in droplets without these restrictions. Monte Carlo Simulation (MCS), with an appropriate mathematical model, creates the opportunity to examine tens of thousands of different scenarios in a few minutes. As such, this work aims to develop a kinetic model of UV disinfection in dried droplets and use this model to inform us about the disinfection of viruses in dried droplets using MCS.

\section{Model Development}

Disinfection is typically modelled as first order process where the rate of change of the number of surviving organisms is proportional to the dose received. The ratio of surviving organism $\left(N / N_{0}\right)$ is given by:

$\frac{N}{N_{o}}=e^{-k D}$

In the case of UV, dose $(D)$ is the product of the light intensity $\left(\mathrm{mW} / \mathrm{cm}^{2}\right)$ the organism receives and the duration of exposure (s). The parameter $k$ is a disinfection rate constant $\left(\mathrm{cm}^{2} / \mathrm{mJ}\right)$.

Tseng and $\mathrm{Li}$ (2007) showed good agreement with the first order model when disinfecting-viruses with UV on surfaces, with $\mathrm{R}^{2}$ values of $0.94,0.96,0.96$, and 0.98 for MS2, $\Phi$ X174, $\Phi 6$, and T7 viruses, respectively. The lower UV sensitivity of viruses on surfaces when compared to aerosols observed by Tseng and $\mathrm{Li}$ (2007) was postulated to involve the presence of aggregates on the surface, which is addressed below.

Hard-to-disinfect aggregates of organisms, often associated with small particles, is a historical problem in UV disinfection (Azimi et al., 2013, 2012; Emerick et al., 2000; Loge, 1996). Mathematical models developed to describe this behavior include that of Emerick et al. (2000), which introduced a parameter for the number of particle associated organisms $\left(N_{p}\right)$. Since they are harder to disinfect, the rate of 
inactivation of $N_{p}$ was assumed to be linear with time, rather than exponential. Other authors have used double-exponential models where the process remains first order, with different exponential rate constants for single organisms $\left(k_{S}\right)$ and a smaller one for particle-associated aggregates $\left(k_{A}\right)$ (Azimi et al., 2012; Barbeau et al., 2005). The model used in this work is of the double-exponential type, and is adapted from Barbeau et al. (2005) shown below:

$$
\frac{N}{N_{o}}=(1-\beta) e^{-k_{S} D}+\beta e^{-k_{A} D}
$$

In this model, $k_{S}$ is the rate constant for single organisms; $k_{A}$ is the rate constant for aggregates; $D$ is the UV dose; and $\beta$ is the fraction of the population in aggregates. The rate constant for aggregates is smaller than that of individual organisms, consistent with the fact that they are harder to disinfect. In reality, there is most likely a distribution of rate constants (i.e. more than two) but the current scientific literature precludes us from defining rate constants based on aggregate characteristics. One advantage of this relatively simple model is the small number of parameters that must be estimated, which is important for modelling. This model can also help to identify what are the aggregate characteristics that control the value of $k_{A}$.

\section{Monte Carlo Simulation}

Monte Carlo Simulation can be used to account for variability and uncertainty. Variables can be assigned statistical distributions that reflect the level of uncertainty in their estimation. In this case, the model is executed 10,000 times, each time taking a random sample of the uncertain variables. Increasing the number of model executions to 15,000 produced results that agreed with 10,000 executions within $1 \%$, suggesting a sufficient number had been used. The results are tabulated to see what fraction of a given log reduction in $\mathrm{N} / \mathrm{N}_{\mathrm{o}}$ is exceeded. This allows an estimate of performance, even if some of the parameters are uncertain or variable.

The most uncertain parameter in this work is the fraction of the viral population in aggregates $(\beta)$. Johnson et al. (2011) showed that the diameter of saliva droplets produced by speaking followed a lognormal distribution, so $\beta$ is also assumed to be lognormal. Since there is a high degree of uncertainty in estimating $\beta$, a relatively large standard deviation is assumed for this lognormal distribution: $80 \%$ of the mean. Figure 1 show the distribution of $\beta$ used in this work. Note that the mean value is about $2 \%$, but values as low as $0.4 \%$ and as high as $7.6 \%$ are possible.

There is less uncertainty in the single organism disinfection rate constant $\left(k_{S}\right)$, since published values are often available. However, the aggregate rate constant $\left(k_{A}\right)$, as discussed previously, is more uncertain, with few values found in the literature. To account for this uncertainty, $k_{A}$ is assumed to be normally distributed with a standard deviation of $50 \%$ of the mean. 
One of the advantages of the relatively simple model used here is that only three parameters are needed: $k_{S}, k_{A}$, and $\beta$. Of these, $k_{S}$ is the easiest to estimate. Based on the recent review of Hessling et al. (2020), the median observed value for $k_{S}$ for several different coronaviruses is approximately $0.22 \mathrm{~cm}^{2} / \mathrm{mJ}$. This is consistent with observed cluster of values for SARS-CoV-1, MS2, and $\Phi 6$ viruses published by lii et al. (2020). The published value for SARS-CoV-1 in this cluster has a $k_{S}$ value of approximately $0.18 \mathrm{~cm}^{2} / \mathrm{mJ}$. Taking the average, a value of $0.20 \mathrm{~cm}^{2} / \mathrm{mJ}$ is used for the $k_{S}$ of SARS-CoV-2 in this work.

The fraction of viruses in aggregates $(\beta)$ is more uncertain. From the model validation work, described below, the values of $\beta$ were observed to be $2 \%$ and $13 \%$ for $2 \mu \mathrm{L}$ and $10 \mu \mathrm{L}$ droplets, respectively. This suggests $\beta$ decreases as droplets get smaller. The actual droplets we are interested in are much smaller than $2 \mu \mathrm{L}$, on the order of $0.002 \mu \mathrm{L}$. Nonetheless, we will conservatively assume a mean value for $\beta$ of $2 \%$ for disinfection of SARS-CoV-2. This ensures there is some safety factor in any disinfection predictions.

Estimating $k_{A}$ for SARS-CoV-2 is also difficult, but there is some previous work on particle-associated bacteria on which we can draw. Azimi et al. (2012) observed a ratio of $k_{A} / k_{S}$ of $6 \%$. Kollu and Örmeci (2012) observed an approximate ratio of $k_{A} / k_{S}$ of $15 \%$. The ratio of $k_{A} / k_{S}$ in the model validation in this work was $12 \%$. Therefore, we assign a median value of $k_{A} / k_{S}$ of $10 \%$ in this work based on other observations. This gives a value of $k_{A}$ of $0.020 \mathrm{~cm}^{2} / \mathrm{mJ}$ for SARS-CoV-2 $\left(10 \%\right.$ of $\left.k_{S}\right)$. Table 1 shows an overview of the model inputs used for $B$. subtilis spores and SARS-CoV-2.

Table 1 Monte Carlo Simulation parameters*

\begin{tabular}{|c|c|c|c|c|}
\hline $\begin{array}{l}\text { Test } \\
\text { Organism }\end{array}$ & Model Parameter & $\begin{array}{l}\text { Distribution } \\
\text { type }\end{array}$ & $\begin{array}{l}\text { Mean } \\
\text { Value }\end{array}$ & $\begin{array}{l}\text { Standard deviation (\% } \\
\text { of mean) }\end{array}$ \\
\hline \multirow[t]{3}{*}{$\begin{array}{l}\text { B. subtilis } \\
\text { spores }\end{array}$} & $\begin{array}{l}\text { Single organism rate constant } \\
(k s)\end{array}$ & $\mathrm{n} / \mathrm{a}$ & $\begin{array}{l}0.10 \\
\mathrm{~cm}^{2} / \mathrm{mJ}\end{array}$ & $\mathrm{n} / \mathrm{a}$ \\
\hline & $\begin{array}{l}\text { Aggregate disinfection rate } \\
\text { constant }\left(k_{A}\right)\end{array}$ & Normal & $\begin{array}{l}0.012 \\
\mathrm{~cm}^{2} / \mathrm{mJ}\end{array}$ & $0.006(50 \%)$ \\
\hline & $\begin{array}{l}\text { Fraction of particle associated } \\
\text { organisms }(\beta)\end{array}$ & Lognormal & $2 \%$ & $1.8 \%(80 \%)$ \\
\hline \multirow[t]{3}{*}{$\begin{array}{l}\text { SARS-CoV- } \\
2\end{array}$} & $\begin{array}{l}\text { Single organism rate constant } \\
(k s)\end{array}$ & $\mathrm{n} / \mathrm{a}$ & $\begin{array}{l}0.20 \\
\mathrm{~cm}^{2} / \mathrm{mJ}\end{array}$ & $\mathrm{n} / \mathrm{a}$ \\
\hline & $\begin{array}{l}\text { Aggregate disinfection rate } \\
\text { constant }\left(k_{A}\right)\end{array}$ & Normal & $\begin{array}{l}0.020 \\
\mathrm{~cm}^{2} / \mathrm{mJ}\end{array}$ & $0.010(50 \%)$ \\
\hline & $\begin{array}{l}\text { Fraction of particle associated } \\
\text { organisms }(\beta)\end{array}$ & Lognormal & $2 \%$ & $1.8 \%(80 \%)$ \\
\hline
\end{tabular}


* See Model Development section for details of parameter estimation

\section{Results}

Model Validation

Laboratory disinfection work commonly uses less hazardous surrogates in place of more dangerous ones. The work of Barancheshme et al. (2021) used relatively difficult to disinfect, B. subtilis spores in dried human saliva droplets in a UV disinfection study.

Figure 2 shows the results of Barancheshme et al. (2021) on B. subtilis spores fitted to a doubleexponential model for $2 \mu \mathrm{L}$ and $10 \mu \mathrm{L}$ droplets. Note that both rate constants $\left(k_{S}\right.$ and $\left.k_{A}\right)$ have the same values independent of droplet size. The only difference between the figures is the fraction of organisms found in aggregates $(\beta)$, which decreases with droplet size from $13-2 \%$. The two-population, doubleexponential model effectively described the UV disinfection of $B$. subtilis spores in dried human saliva resulting in $R^{2}$ values of 0.98 and 0.97 for $2 \mu \mathrm{L}$ and $10 \mu \mathrm{L}$ droplets, respectively. These results suggest that the rate constants are indeed constant, and the effects of droplet size can be approximated by changing the $\beta$ alone.

Monte Carlo Simulation of $B$. subtilis Spore UV inactivation

In reality, the number of organisms associated with aggregates is both variable and uncertain, since not two coughs are exactly the same. Based on the previous model validation, this variability is approximated by changing the parameter $\beta$. The precise value of $k_{A}$ is also not known, only approximated, so a normal distribution is used to account for this. Allowing for this uncertainty, Table 2 shows the expected log reduction in $B$. subtilis spores in dried saliva droplets.

Table 2 Probability of achieving different log reductions in $B$. subtilis spores as a function of UV dose (Monte Carlo simulation with 10,000 model executions)

\section{$\operatorname{Dose}\left(\mathrm{mJ} / \mathrm{cm}^{2}\right)$}

\begin{tabular}{lllllll}
\hline & 20 & 40 & 60 & 80 & 100 & 120 \\
\hline$>1 \log$ & $<0.1 \%$ & $>99.9 \%$ & $>99.9 \%$ & $>99.9 \%$ & $>99.9 \%$ & $>99.9 \%$ \\
\hline$>2 \log$ & $<0.1 \%$ & $<0.1 \%$ & $33 \%$ & $64 \%$ & $75 \%$ & $81 \%$ \\
\hline$>3 \log$ & $<0.1 \%$ & $<0.1 \%$ & $<0.1 \%$ & $<0.1 \%$ & $1 \%$ & $4 \%$
\end{tabular}

The results of the MCS show that there are diminishing returns as UV dose is increased. One-log reduction can be achieved at a dose of $40 \mathrm{~mJ} / \mathrm{cm}^{2}$. However, doubling this dose to $80 \mathrm{~mJ} / \mathrm{cm}^{2}$ shows that a two-log reduction will be achieved only $64 \%$ of the time. Tripling the dose to $120 \mathrm{~mJ} / \mathrm{cm}^{2}$ only increases the chances of two-log (or more) reduction to just $81 \%$. The rate constant for aggregates, 
important at higher log reductions, is an order of magnitude smaller than that of single organisms. Also, aggregates are variable in this model, and it gets more unlikely to achieve complete inactivation at the higher doses where they dominate. For example, some of the time, aggregates will contain such a large fraction of the total population a high log reduction is difficult to achieve.

Monte Carlo Simulation of SARS-CoV-2 Inactivation

The single organism rate constant $\left(k_{S}\right)$ for SARS-CoV-2 used in this work is twice that of $B$. subtilis spores $\left(0.20 \mathrm{vs} .0 .10 \mathrm{~cm}^{2} / \mathrm{mJ}\right)$. In addition, the aggregate rate constant $\left(k_{A}\right)$ is assumed to be proportional to the single organism disinfection sensitivity $\left(k_{S}\right)$, making both rate constants larger. These higher rate constants make the log reductions that can be achieved with SARS-CoV-2 greater than that of $B$. subtilis spores (Table 3).

For example, a one-log reduction in SARS-CoV-2 is very likely ( $p>99.9 \%$ ) at a dose of just $20 \mathrm{~mJ} / \mathrm{cm}^{2}$, but very unlikely for $B$. subtilis spores $(p<0.1 \%)$. At $40 \mathrm{~mJ} / \mathrm{cm}^{2}$, the probability of exceeding a two-log reduction in SARS-CoV-2 is $55 \%$, where it is $<0.1 \%$ for $B$. subtilis spores. Overall, this makes $B$. subtilis spores a conservative surrogate for SARS-CoV-2.

Table 3 Probability of achieving different log reductions in SARS-CoV-2 as a function of UV dose (Monte Carlo simulation with 10,000 model executions)

\section{Dose $\left(\mathrm{mJ} / \mathrm{cm}^{2}\right)$}

\begin{tabular}{lllllll}
\hline & 20 & 40 & 60 & 80 & 100 & 120 \\
\hline$>1 \log$ & $>99.9 \%$ & $>99.9 \%$ & $>99.9 \%$ & $>99.9 \%$ & $>99.9 \%$ & $>99.9 \%$ \\
\hline$>\mathbf{2} \log$ & $<0.1 \%$ & $55 \%$ & $75 \%$ & $84 \%$ & $89 \%$ & $91 \%$ \\
\hline$>$ 3 log & $<0.1 \%$ & $<0.1 \%$ & $1 \%$ & $7 \%$ & $19 \%$ & $33 \%$
\end{tabular}

Once again, even for the more UV sensitive SARS-CoV-2, aggregates limit the ability to achieve high log reductions, in this model. Doubling the dose from 60 to $120 \mathrm{~mJ} / \mathrm{cm}^{2}$ increases the probability of two-log reduction from $75-91 \%$, an increase of just $17 \%$. The probability of achieving greater than a three-log reduction never exceeds $33 \%$. This suggests the three-log reductions are likely difficult to achieve in this conservative model. In practical terms, a two-log reduction of SARS-CoV-2 in dried saliva droplets is likely a reasonable target.

According to the model, a one-log reduction is very likely (>99.9\%) and a two-log reduction is probable ( $\mathrm{p}$ $=75 \%$ ) for SARS-CoV-2 at a dose of $60 \mathrm{~mJ} / \mathrm{cm}^{2}$. This is likely a practical dose to aim for. Figure 3 shows the distribution of log reductions at this dose. Note that both low $(<1.3)$ and high $(>3.2)$ log reductions are observed, illustrating the variable nature of dried droplets in this model. 


\section{Model Limitations}

The assumptions of the model are described in the Model Development section. Briefly, we assume that UV disinfection of dried saliva is similar to UV disinfection in other liquids containing aggregates and/or particles. The Model Validation section shows that the observed disinfection of $B$. subtilis spores in dried saliva could be described in this way with $R^{2} \geq 0.97$. The fraction of organisms in aggregates is estimated using a single parameter $\beta$, where in reality the situation is likely much more complex. However, even if $\beta$ could be determined experimentally, there is no guarantee that a different cough or sneeze would produce the same result. Nonetheless, a better understanding how viruses are distributed in dried droplets could improve this model. The single organism rate constant for SARS-CoV-2, on which so much depends, is approximate and based on the literature and not actual experiments. This also could be improved.

Lastly, the validation work was done using bacterial spores, and some of this information was extrapolated to viruses. This size discrepancy between viruses and bacteria likely contributes more uncertainty in $\beta$ and $k_{A}$ for SARS-CoV-2. However, some uncertainty in these parameters was accounted for in the MCS. In addition, an appropriate single organism rate constants $\left(k_{S}\right)$ was used for SARS-CoV-2, and $k_{S}$ describes most of the behavior at low log reductions. High log reductions are uncertain, and this is reflected in the model.

Overall, double-exponential, three-parameter model that can describe UV disinfection in dried saliva droplets is proposed. Applying this simple model to SARS-CoV-2 disinfection suggests the one-log reductions are very likely $(p>99.9 \%)$ and two-log reductions are probable $(p=75 \%)$ at a dose of 60 $\mathrm{mJ} / \mathrm{cm}^{2}$.

\section{Conclusions}

In this work, we demonstrated the UV disinfection of $B$. subtilis spores in dried human saliva could be described by a two-population, double-exponential model $\left(R^{2} \geq 0.97\right)$ where $\beta$ is the fraction of organisms in aggregates. The value of $\beta$ was $2 \%$ for dried $2 \mu \mathrm{L}$ droplets and decreased with droplet size. Since no two coughs are exactly the same, we assume that $\beta$ is variable and it was assigned a lognormal distribution. Monte Carlo simulation (MCS) of $B$. subtilis spores and SARS-CoV-2 showed increases in the resistance to UV disinfection and increases in the variability in the results at higher log reductions. This was attributed to the lower disinfection rate constant for aggregates $\left(k_{A}\right)$ and the variable nature of droplets. It was shown, using a conservative estimation of $\beta$ for very small droplets, that a two-log reduction of SARS-CoV-2 was probable $(\mathrm{p}=75 \%)$ at a dose of $60 \mathrm{~mJ} / \mathrm{cm}^{2}$. Higher log reductions are more uncertain and difficult to achieve. Future work should investigate the impact of dried droplets characteristics on the kinetic parameters of the double-exponential model.

\section{Declarations}




\section{Ethics approval and consent to participate:}

This study did not involve human participants, human data or human tissue.

\section{Consent for publication:}

Consent was provided by one the co-authors of this study (Barbeau) to use experimental results from and his earlier study (Barancheshme et al., 2021).

\section{Availability of data and materials:}

The datasets used and/or analysed during the current study are available from the corresponding author on reasonable request.

\section{Competing interests:}

The authors declare that they have no competing interests.

\section{Funding:}

No outside funding was provided for this low-cost, modelling study.

\section{Author Contribution:}

JG conceptualized work, did the numerical analysis, and wrote first draft of report

RF provided financial support in the form of a research associate position for JG. Also provided editorial comments on draft repot.

BB provided experimental data used in validating model and editorial comments and suggestions for draft report.

\section{References}

1. Azimi, Y., Allen, D.G., Farnood, R.R., 2012. Kinetics of UV inactivation of wastewater bioflocs. Water Res. 46, 3827-3836. https://doi.org/10.1016/j.watres.2012.04.019

2. Azimi, Y., Chen, X., Allen, D.G., Pileggi, V., Seto, P., Droppo, I.G., Farnood, R.R., 2013. UV disinfection of wastewater flocs: the effect of secondary treatment conditions. Water Sci. Technol. 67, 2719-2723. https://doi.org/10.2166/wst.2013.148 
3. Barancheshme, F., Philibert, J., Noam-Amar, N., Gerchman, Y., Barbeau, B., 2021. Assessment of saliva interference with UV-based disinfection technologies. J. Photochem. Photobiol. B 217, 112168. https://doi.org/10.1016/j.jphotobiol.2021.112168

4. Barbeau, B., Huffman, D., Mysore, C., Desjardins, R., Clément, B., Prévost, M., 2005. Examination of discrete and counfounding effects of water quality parameters during the inactivation of MS2 phages and Bacillus subtilis spores with chlorine dioxide. J. Environ. Eng. Sci. 4, 139-151. https://doi.org/10.1139/s04-050

5. Beck, S.E., Rodriguez, R.A., Hawkins, M.A., Hargy, T.M., Larason, T.C., Linden, K.G., 2016. Comparison of UV-Induced Inactivation and RNA Damage in MS2 Phage across the Germicidal UV Spectrum. Appl. Environ. Microbiol. 82, 1468-1474. https://doi.org/10.1128/AEM.02773-15

6. Bedell, K., Buchaklian, A.H., Perlman, S., 2016. Efficacy of an Automated Multiple Emitter WholeRoom Ultraviolet-C Disinfection System Against Coronaviruses MHV and MERS-CoV. Infect. Control Hosp. Epidemiol. 37, 598-599. https://doi.org/10.1017/ice.2015.348

7. Chiappa, F., Frascella, B., Vigezzi, G.P., Moro, M., Diamanti, L., Gentile, L., Lago, P., Clementi, N., Signorelli, C., Mancini, N., Odone, A., 2021. The efficacy of UV light-emitting technology against coronaviruses: a systematic review. J. Hosp. Infect. S0195670121002085. https://doi.org/10.1016/j.jhin.2021.05.005

8. Dbouk, T., Drikakis, D., 2020. On coughing and airborne droplet transmission to humans. Phys. Fluids 32, 053310. https://doi.org/10.1063/5.0011960

9. Emerick, R.W., Loge, F.J., Ginn, T., Darby, J.L., 2000. Modeling the inactivation of particle-associated coliform bacteria. Water Environ. Res. 72, 432-438.

10. Hessling, M., Hones, K., Vatter, P., Lingenfelder, C., 2020. Ultraviolet irradiation doses for coronavirus inactivation - review and analysis of coronavirus photoinactivation studies. GMS Hyg. Infect. Control 15.

11. lii, E.R.B., Petri, B., Sun, W., 2020. SARS-CoV-2 UV Dose-Response Behavior 6.

12. Jagger, J., 1967. Introduction to research in ultraviolet photobiology. Prentice-Hall, Englewood Cliffs, N.J.

13. Johnson, G.R., Morawska, L., Ristovski, Z.D., Hargreaves, M., Mengersen, K., Chao, C.Y.H., Wan, M.P., Li, Y., Xie, X., Katoshevski, D., Corbett, S., 2011. Modality of human expired aerosol size distributions. J. Aerosol Sci. 42, 839-851. https://doi.org/10.1016/j.jaerosci.2011.07.009

14. Kollu, K., Örmeci, B., 2012. Effect of particles and bioflocculation on ultraviolet disinfection of Escherichia coli. Water Res. 46, 750-760. https://doi.org/10.1016/j.watres.2011.11.046

15. Loge, F.J., 1996. Ultraviolet Disinfection of Secondary Wastewater Effluents: Prediction of Performance and Design 18.

16. Ma, B., Linden, Y.S., Gundy, P.M., Gerba, C.P., Sobsey, M.D., Linden, K.G., 2021. Inactivation of Coronaviruses and Phage Phi6 from Irradiation across UVC Wavelengths. Environ. Sci. Technol. Lett. acs.estlett.1c00178. https://doi.org/10.1021/acs.estlett.1c00178

17. Masschelein, W.J., 2002. Ultraviolet Light in Water and Wastewater Sanitation. Lewis Publishers. 
18. Noorimotlagh, Z., 2020. A systematic review of emerging human coronavirus (SARS-CoV-2) outbreak: focus on disinfection methods, environmental survival, and control and prevention strategies. Env. Sci Pollut Res 15.

19. Pfaender, S., Brinkmann, J., Todt, D., Riebesehl, N., Steinmann, Joerg, Steinmann, Jochen, Pietschmann, T., Steinmann, E., 2015. Mechanisms of Methods for Hepatitis C Virus Inactivation. Appl. Environ. Microbiol. 81, 1616-1621. https://doi.org/10.1128/AEM.03580-14

20. Simmons, S.E., Carrion, R., Alfson, K.J., Staples, H.M., Jinadatha, C., Jarvis, W.R., Sampathkumar, P., Chemaly, R.F., Khawaja, F., Povroznik, M., Jackson, S., Kaye, K.S., Rodriguez, R.M., Stibich, M.A., 2021. Deactivation of SARS-CoV-2 with pulsed-xenon ultraviolet light: Implications for environmental COVID-19 control. Infect. Control Hosp. Epidemiol. 42, 127-130. https://doi.org/10.1017/ice.2020.399

21. Tseng, C.-C., Li, C.-S., 2007. Inactivation of Viruses on Surfaces by Ultraviolet Germicidal Irradiation. J. Occup. Environ. Hyg. 4, 400-405. https://doi.org/10.1080/15459620701329012

\section{Figures}

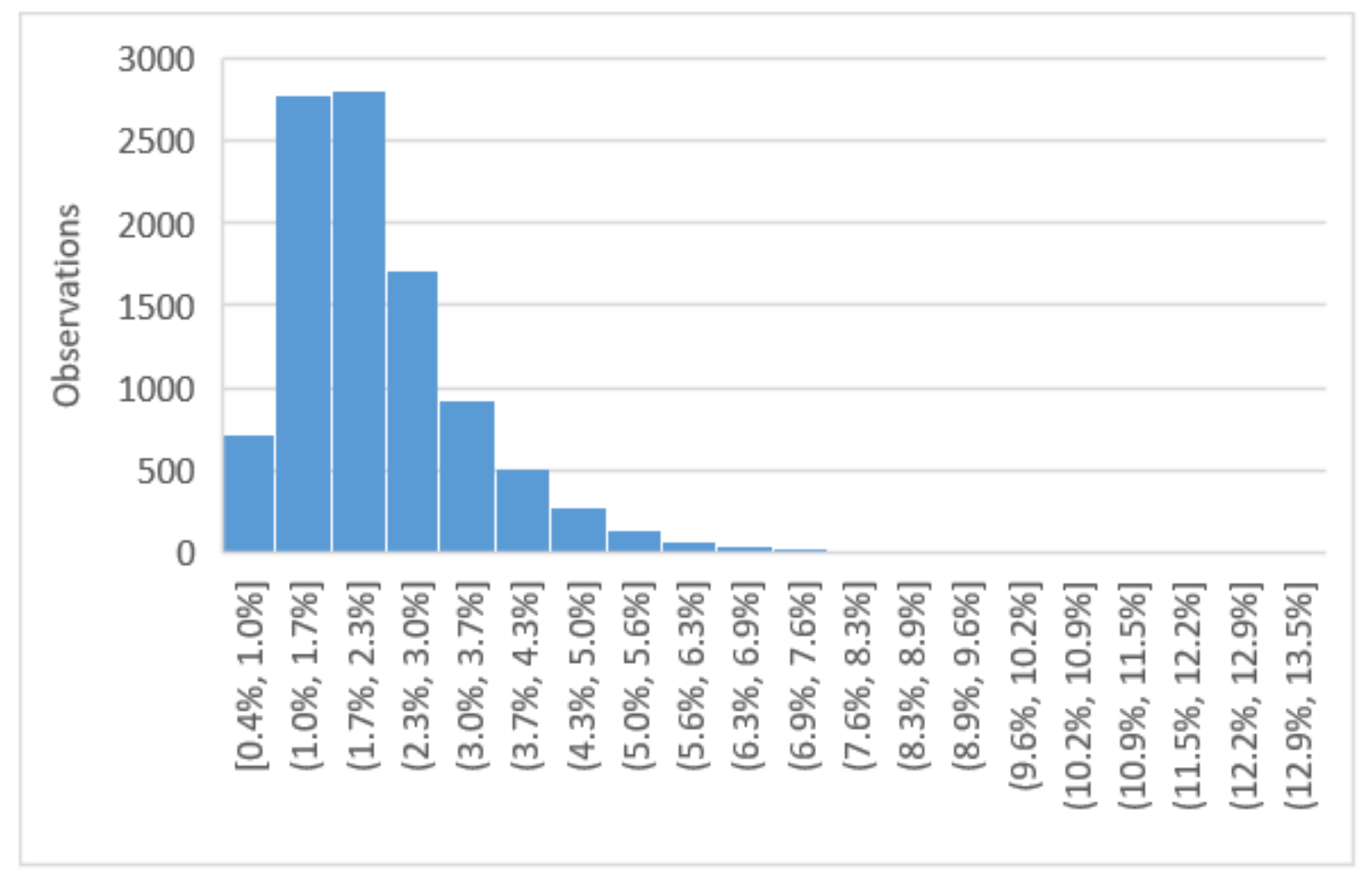

\section{Figure 1}

Distribution of the fraction of the population found in aggregates $(\beta)$ used in this work $(10,000$ simulations). 
- Observed Model

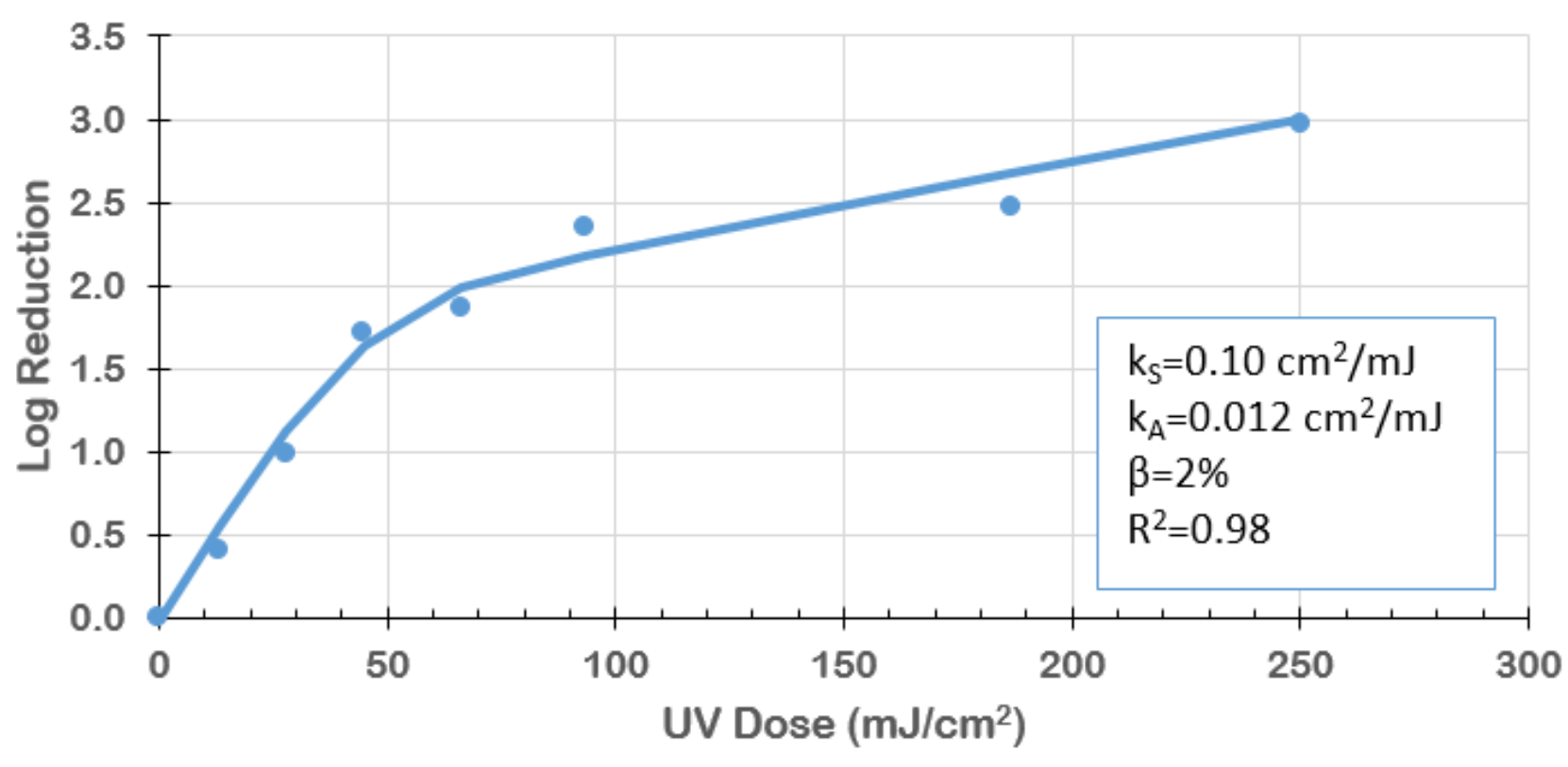

- Observed Model

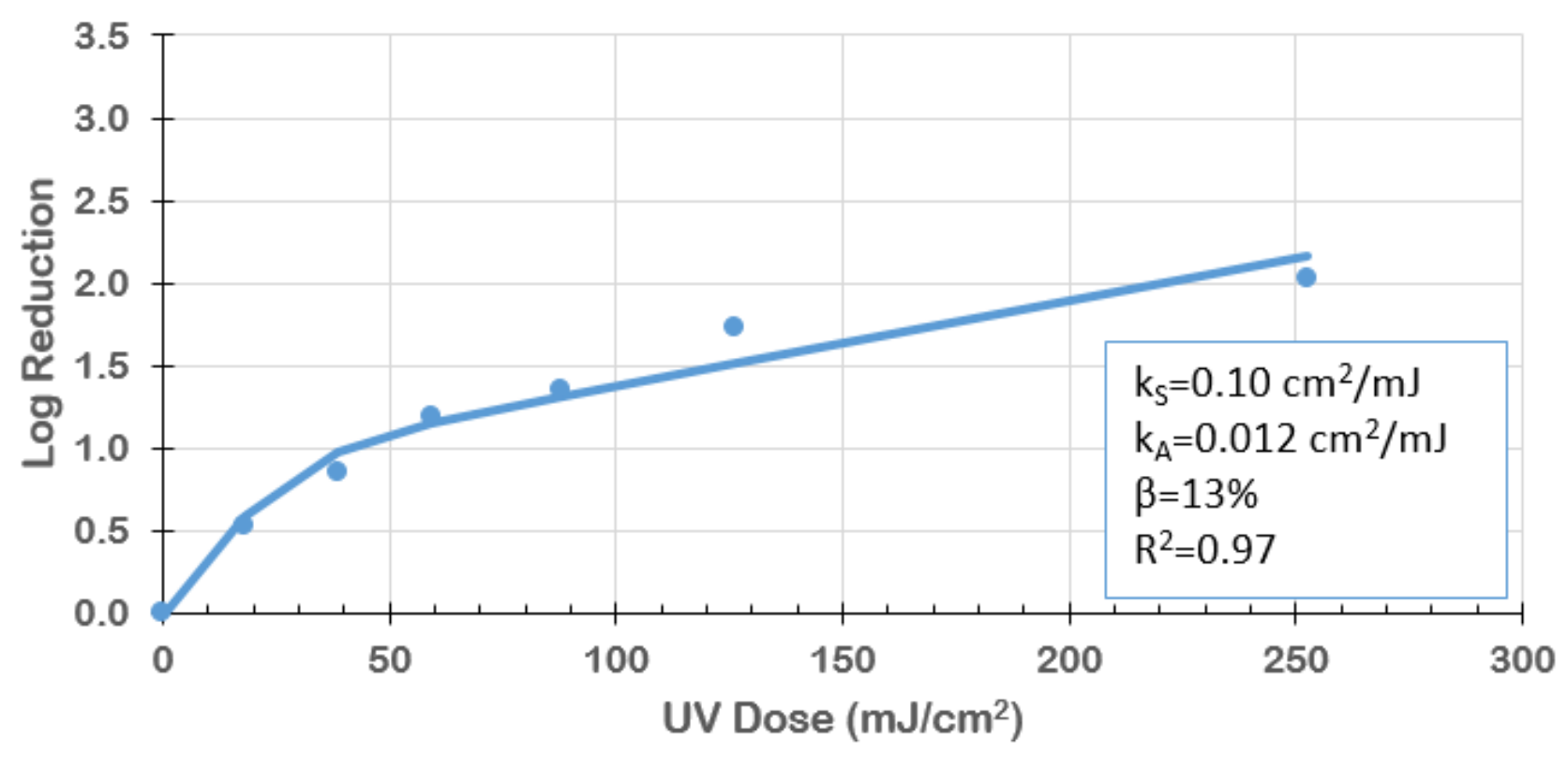

\section{Figure 2}

UV disinfection of B. subtilis spores in human saliva in dried $2 \mu \mathrm{L}(\mathrm{A})$ and $10 \mu \mathrm{L}(\mathrm{B})$ droplets fitted to a double-exponential model. ( $\mathrm{kS}=$ rate constant for single organisms; $\mathrm{kA}=$ rate constant for aggregates; $\beta$ $=$ fraction of organisms in aggregates) 


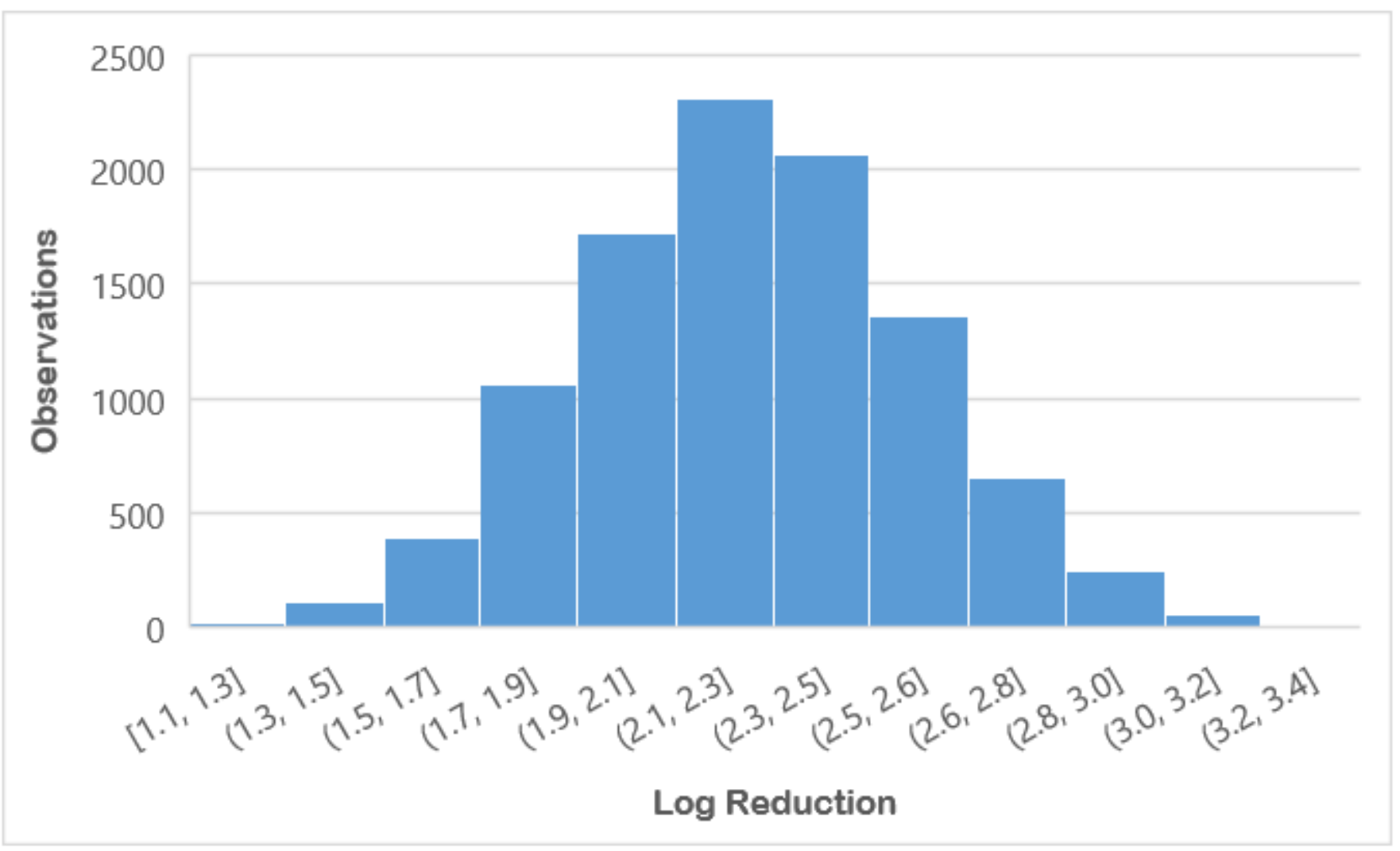

Figure 3

Log reductions of SARS-CoV-2 in dried saliva droplets at a UV dose of $60 \mathrm{~mJ} / \mathrm{cm} 2(10,000$ model executions) 